\title{
Urban Planning in Post-Apartheid South African Cities: The Case of Johannesburg
}

\author{
Simona Totaforti \\ University for Foreigners “Dante Alighieri” of Reggio Calabria, Reggio Calabria, Italy \\ Email: totaforti@unistrada.it
}

How to cite this paper: Totaforti, $S$. (2020). Urban Planning in Post-Apartheid South African Cities: The Case of Johannesburg. Open Journal of Political Science, 10, 507-520.

https://doi.org/10.4236/ojps.2020.103031

Received: June 28, 2020

Accepted: July 7, 2020

Published: July 10, 2020

Copyright (c) 2020 by author(s) and Scientific Research Publishing Inc. This work is licensed under the Creative Commons Attribution International License (CC BY 4.0).

http://creativecommons.org/licenses/by/4.0/

(c) (i) Open Access

\begin{abstract}
This paper reflects on the question of urban growth in South Africa to understand the consequences that new urban dynamics have on the effective rights to the city and on quality of life; and, in the context of urban studies, on the southern turn and on the effective possibility of applying the paradigms produced by the Global North to the countries of the Global South and emerging economies. There is a growing interest in analyzing the reasons behind the cultural and organizational differences that typify African cities. In this scenario, the contribution of urban studies is crucial to understand how cities work, the needs of their residents and the changes that take place, especially in cities like Johannesburg whose urban fabric still shows traces of racial segregation and class division stemming from apartheid. By considering Johannesburg as a case in point, this paper sets out to investigate whether the diversity and differentiation of the urban spaces that characterize South African cities as seemingly unreadable, chaotic and difficult to understand and govern reflect on the one hand the role of the social forces that shape the built environment and urban planning, and on the other hand social and racial inequalities, the actual enjoyment of the right to the city, the identity-defining features of urban space. In other words, the article intends to investigate the outcomes of the interaction between the superficial layers of the urban landscape (for example, the transformations of the built environment) and the deep structural forms that are rooted in the local history and memory.
\end{abstract}

\section{Keywords}

Urban Policies, South Africa, African Cities, Johannesburg, Poverty

\section{Introduction}

The United Nations Report World social situation 2019. shaping the future of inequality highlights the impact of four major global trends around Sustainable 
Development Goal 10 "Reduced inequalities". Climate change, urbanization, international migration and technological innovation are assessed in relation to their impact on inequality and from a perspective that includes various aspects of human well-being. "Inequality," reads the note, "hinders progress towards achievement of the Sustainable Development Goals. For example, highly unequal societies are less effective at reducing poverty than those with low levels of inequality. They also grow more slowly and are less successful at sustaining economic growth over long periods of time" (UN, 2019).

Earlier, in 2015, the United Nations had already pointed out that population growth in the $21^{\text {st }}$ century will be concentrated mainly in Africa and Asia (UN-DESA, 2015). In particular, Africa is experiencing unprecedented urban growth. It is estimated that by 2050 the African population will double from 1.2 to 2.5 billion inhabitants, and cities will be the outpost of this demographic revolution, as they will see around $2 / 3$ of this growth. Therefore, while on the one hand African cities are becoming increasingly important internationally as key economic centers of production and exchange, on the other hand, rapid and often uncontrolled urban expansion poses many challenges. Existing urban infrastructures are generally inadequate to respond to the demographic pressure and needs of a part of the population that still lives at the margins of society. Informal settlements are growing and actions often prove inadequate to deal with socio-political and economic dynamics and to guarantee citizenship rights. In other words, the issues do not only concern the analysis of the consequences of urban development in African cities, but also the development of new paradigms-or the assessment of the adequacy of traditional ones-to understand the consequences that new urban dynamics have on the effective rights to the city and on quality of life. According to Amin and Thrift, "if cities are growth machines whose intensities are regulated by their infrastructural conditions, they are also machines of marked socioeconomic disparity. In cities, wellbeing and want coexist, their interdependencies and separations maintained by the same meshwork of institutions and infrastructures" (Amin \& Thrift, 2018: p. 125). Therefore, the growing interest in African studies shown in many disciplines, including urban studies, is also due to the awareness that the analysis of urbanization processes allows us to understand the intensity and distribution of poverty in urban contexts and to design targeted, inclusive and forward-looking policies. However, if we consider the "frames of inference" existing between urban infrastructure and the measure of poverty or the analysis of its causes, there appears to be no consensus on whether the city accentuates this condition or, conversely, offers more opportunities. This aspect is particularly interesting when applied to cities in the Global South (Amin \& Thrift, 2018).

Indeed, recently, precisely in the context of urban studies, the debate has taken a southern turn and centered on the effective possibility of applying the paradigms produced by the Global North to the countries of the Global South and emerging economies. Traditionally, in fact, studies on the nature of the city and on actions and interventions to improve the quality of urban life are based on 
the features of the Global North regions which, according to the Southern theorists, are not suited to the regions of the Global South. At the same time, with reference to South African cities one can emphasize that their huge diversity and the differentiation of urban spaces have produced an imaginary that is seemingly unreadable, chaotic and difficult to govern at the urban level. By considering Johannesburg as a case in point, this paper sets out to investigate on the one hand the role of the social forces that shape the built environment and urban planning, and on the other hand social and racial inequalities, the actual enjoyment of the right to the city, the identity-defining features of urban space. In other words, the article intends to investigate the outcomes of the interaction between the superficial layers of the urban landscape (for example, the transformations of the built environment) and the deep structural forms that are rooted in the local history and memory, to understand whether the instability and irregular patterns that characterize the built environment and urban development are the result of a gap between the city and its representation, that is to say between the temporary nature that is typical of informal lives and the efforts to apply traditional models and paradigms of development that belong to the Global North.

\section{Urbanization in South Africa}

The history of urban planning and housing policies in South Africa-as in the rest of the African continent-has been shaped by concepts, models and approaches taken mainly from the Global North and uncritically applied to the Global South. This process formed an integral part of colonial history and it has left traces in the urban fabric of the major South African cities and in the models used today for urban planning. For example, during apartheid, radio-centric Garden cities (the Howard's Garden City movement inspired communities across Europe as far afield as South Africa and South America, Howard, 1945), satellite towns (e.g. Johannesburg and its satellite towns on the East and West Rand developed at the beginning of the $20^{\text {th }}$ century; Erasmus, 2014: p. 346), neighbourhood units or other western-based models promoted and legitimized urban racial segregation strategies and the displacement of black families towards the suburbs (the physical and social characteristics of the apartheid city have been extensively documented: Parker, 2015; Christopher, 2000; Western, 1996; Lemon, 1991; Davies, 1981). The effects are still visible today in the urban fabric of many African cities, and new urban policies, while inspired by change actions, continue to perpetuate a type of urban planning that encourages inequalities, poverty and social marginalization (by the late 1980s, the nature of the post-apartheid city have been hugely analysed: Davies, 1996; Kotze \& Donaldson, 1998; Oelofse \& Dodson, 1997; Beavon, 1992; Tomlinson, 1990; Hart, 1989). The notion that places matter, whether they are in the North or the South of the world, has gained traction in the last 20 years, bringing a predominantly epistemological change, that is, cantered on theoretical approaches and on the methodologies of how knowledge is produced. In fact, according to Dados and Connell, "the phrase Global South marks a shift from a central focus on devel- 
opment on cultural difference towards an emphasis on geopolitical relations of power" (Dados \& Connell, 2012: pp. 12-13). We are therefore not referring to a physical and geographical space, but to a different perspective that tries to overcome the traditional way of conceptualizing the world to build a new one that is capable of providing valuable insights not only on the Global South, but also with reference to its relations with the Global North (Comaroff \& Comaroff, 2012: pp. 113-131).

Indeed, the ways in which African societies are progressively urbanizing do not seem compatible with the theories and models that traditionally define urban dynamics. As Ferguson observes, "the breadth, diversity, and complexity of the continent and its urban areas seem to make it absurd and reductionist to speak of "the African city", or even the "African cities" [...] as if there is a type, or even several types that belong to a distinct set" (Ferguson, 2006: p. 3). This approach does not consider the differences and specific features of places and cultures, but above all it expresses an often incorrect and sometimes racist vision of society, which does not take into consideration the vibrancy and complexity of African cities and the variety of experiences that unfold in them. The large differences in the data relating to African cities and their varying reliability make comparisons difficult, further debasing the idea that we can still talk about African urban areas as belonging to a single category. The main issues that are raised are on the one hand the lasting consequences of colonialism and the growing informality of socio-economic life; on the other hand, the dynamics of urban poverty, inequality and socio-political exclusion in African urban contexts, as well as, possibly, the way in which the population reacts by organizing collective and new urban cultures.

Therefore, there is a growing interest in analyzing the reasons behind the cultural and organizational differences that typify African cities. If at one level the utopian Broadacre city-an ideal response by Frank Lloyd Wright to Le Corbusier's Ville Radieuse that was never built, eventually-represented the model for the western functional city, at another level some African cities-as is the case for Lagos in Nigeria, according to Koolhaas-invert the essential characteristics of what is defined as the modern city, but they are nonetheless functional (Parker, 2015). In other words, Koolhaas and The Harvard Project on the City reject the dependence on theoretical models that would describe Lagos as a city in a primitive state of urban evolution compared to the western model, stressing that on the contrary it is "a developed, extreme, paradigmatic case-study of a city at the forefront of globalizing modernity" (Koolhaas \& Harvard Project on the City, 2001: p. 653).

This does not amount to denying the existence of social and spatial inequalities that are expressed above all in the informal housing models of many African cities, where the majority of the black population is forced to live. Townships present serious problems of unemployment, quality of life and services. According to Knox and Marston, "10 million people are dying annually in densely populated urban areas from conditions produced by substandard housing and poor 
sanitation" (Knox \& Marston, 2001: p. 400). However, as Parnell and Robinson argue, there is a different trajectory in African urbanism (e.g. South Africa) that is not aligned with the main trends, and requires further theoretical and interpretive efforts not only with reference to South Africa, but also compared with much of the Global South (Parnell \& Robinson, 2012).

In this regard, Mbembe and Nuttall have made a significant and innovative contribution to the debate, especially regarding the definition of formal and informal, which does not take into account the complexity of the forms and meanings of life in African cities (Mbembe \& Nuttall, 2008: p. 9). In fact, contrary to what is generally pointed out, these aspects are not in opposition, but over time have undergone a form of hybridization. Informal does not mean anti-formal: these are complementary aspects that work together and end up shaping cities and their economy. Urban informality, as Amin argues, is part of the contemporary landscape, and can be considered an "organizational logic" that is becoming increasingly significant in the contemporary era (Amin \& Thrift, 2018; AlSayyad, 2004: p. 26). Clearly, this statement also involves the awareness on the one hand that cities are becoming poorer and more unequal, and on the other hand that there do not seem to be agreed ways to reduce poverty and inequality except, at least in part, by working on a potentially hybrid governance.

African studies have focused on the possibility of defining an alternative theory of justice by taking up Sen's ideas (Sen, 1993, 1999) and in particular his study on the freedom of individuals to choose the kind of life they want to lead and the skills required achieving this goal, which for Sen are essentially relational (Mennasemay, 2009: p. 13). The interesting aspect in this theory lies in the shift of social justice issues from the field of individual rights and distribution, to the very difficult area of perceiving and establishing how societies and their institutions agree and allow individuals to build their own set of images, to surprise themselves and to experience emotions (Nussbaum \& Sen, 1993: p. 1). According to Sen, the opportunities and prospects of the population depend on which institutions exist and how they work (Sen, 1999: p. 142). This last point makes Sen's ideas particularly useful for understanding the concept of justice and its expression in African cities. Therefore, there is a need for new theoretical paradigms that consider not only the legacy of colonial history, but also the specific features of territories that experience rapid urbanization, weak governance by institutions, a large informal economy and extended marginalization, poverty, social vulnerability and inequality.

The legacy of the colonial past-and in South Africa's case apartheid and social polarization on the one hand, and aspiring to live in fairer, more sustainable and more liveable cities on the other-has left its mark on the cities of the Global South in particular. Emerging countries are characterised by rapid urbanization, marked inequality, and enter the global economy-that does not guarantee the principles of equality-with a widespread informal economy. In this scenario, the contribution of urban studies is crucial to understand how cities work, the needs of their inhabitants and the changes that take place, especially in cities like 
Johannesburg whose urban fabric still shows traces of racial segregation and class division stemming from apartheid, when the black population was crammed into townships that evolved from the settlements of shacks surrounding the mines and production plants. In other words, Johannesburg and its paradoxes are a useful case not only from the point of view of the contribution that urban theory can make to African studies, but also regarding empirical aspects aimed at improving the quality of life of urban populations.

\section{Johannesburg's Spatial Landscape}

\subsection{The Dual City}

In Johannesburg, the country's industrial, financial and cultural capital, clear divisions between the north and south of the city are still visible. Murray believes that "Johannesburg after apartheid is a bewildering city, with no dominating downtown or easily recognizable boundaries. With few limits to its horizontal expansion, it has become a sprawling, fragmented metropolis that in large measure resembles a disconnected archipelago of isolated, fortified enclaves unevenly distributed over a vast and highly differentiated territorial expanse" (Murray, 2011: p. 213). Yet, Johannesburg is a two-speed city. The slow pace of repetitive and risky activities-which nurture the poverty of a community that finds an outlet only in the informal economy-coexists with the speed of modernity in the newly built environment and with Africa's first high-speed commuter train connecting the rich north with the inner urban core, where basic services are still lacking for most citizens (Schoenkopf, 2018). Johannesburg is one of the expressions of future urbanism. According to Murray it "is a city of extremes, Southern urbanism in extremis, not just of space and economy, but of time. It is the city located at the intersection of capitalism, time and imagination" (Murray, 2009: pp. 165-192).

Indeed, the analysis of urbanization processes and the development of housing policies in South Africa have traditionally focused on interpreting the city as a product of economic relations based on inequality or on segregationist policies (Mbembe \& Nuttall, 2004). According to Mbembe and Nuttal, this approach is marred by a Eurocentric and colonialist vision that uses categories and parameters that are unsuited to the complexity of the South African reality. Consequently, alongside the traditional interpretation of urban facts, a differently new approach seeks to identify new "levels of meaning", namely "les marques et les produits de grande consommation, les autoroutes et les flux lumineux, les devantures des boutiques et les panneaux publicitaires géants, une architecture nuvelle et, d'une manière générale, la technophilie, éléments qui tous ensemble définissent une esthétique de l'abodance" (Mbembe \& Nuttall, 2004: p. 365). This implies focusing not only on the inhabitants of the slums, migrants and criminals, but also on socially-minded behaviour, qualified migrants and the new black elite.

The goal was to reverse a view of the South African city, and of Johannesburg 
in particular, perpetually linked to vague clichés that do not reflect the complexity of the metamorphosis that is underway. Post-apartheid urban studies were undoubtedly influenced by Mbembe and Nuttal's contributions, and began to consider the new urban images of South African cities, the new forms of expression of urban culture, and to analyse not only South Africa's economic life, but also its social and cultural aspects, which started after the country's extensive political and institutional transformations. However, the risk of this optimistic view, which is opposed to a literature linked to Eurocentric models and approaches, is to overestimate the forms of agency and to overlook the effective weight that power relations have had in slowing down a redefinition of the country's material, political and cultural landscape. As Jacobs states, "la ville sud-africaine d'après l'apartheid, malgré son dynamisme, reste profondément et douloureusement marquée par les relations matérielles, les anciennes bien sûr, mais aussi les nouvelles, qui semblent en train de se solidifier précisément maintenant, à ce moment de la trajectoire politique du pays" (Jacobs, 2006: p. 12). Such material relationships, according to Jacobs (2006), persist and determine a correlation between the distribution of wealth and the segregation of the population on an ethnic basis (Jacobs, 2006).

In this scenario, the establishment of an ideal "good city" based on collective aspirations of social reconstruction must be rethought in order to be effective in South African cities. The transition that characterizes these cities and the analysis of the South African urban experience certainly offers a starting point from which to reshape future interventions, with the awareness that the ideal city, free from discrimination, is probably an illusory ambition (Boraine et al., 2006). Although the right to a just city is not an exclusive feature of post-apartheid cities, the transformations initiated by the democratic revolution in South Africa have highlighted a specificity of these territories that cannot ignore the legacy of the past, which is clearly visible in the physical traces that are present in the urban fabric of the main cities. The post-apartheid transition gave voice to citizens' ambitions and, at the same time, highlighted all the obstacles that slow down or hinder the achievement of the "good city" ideal.

Johannesburg contains many cities in one, where monumental architecture and slums are located, where social polarization is extremely evident and the rich elites coexist with abysmal poverty-although markedly and physically separated (De Boeck, 2002). Johannesburg is a city that expresses both the utopia of progress and the dystopian anguish of marginal realities, and in which collective memory alternates with intentional amnesia. Ongoing urban spreading affects this sprawling city morphologically and impacts the distribution of its population, evolving through planned and involuntary actions and interventions that reflect multiple experiences, lifestyles and the activities that the city offers. The imagery that derives from it-which has been captured in the expression "New York of Africa" or "Heartbeat of South Africa" - shows an obvious ability to reinvent itself and to drive change, but at the same time reveals a troubled history that has yet to find reconciliation with the legacy of the past (Murray, 
2017). So, the resulting image is a prism that reflects on the one hand the social forces that are reshaping the built environment, planning and architecture of the city, and on the other the persistence of social inequalities, creating a national identity and safeguarding citizenship rights. The end of apartheid has initiated a broad debate on the future of the city and the nation aimed at reshaping the urban landscape with a view to achieving racial reconciliation. However, the lack of adequate housing and social security policies, as well as strong inequalities and an economy that is still partially informal, have increasingly raised issues related to the "right to the city" intended both in terms of inclusive and fair urban spaces, and of citizenship rights.

\subsection{Findings: The Spatial Dynamics}

Analyzing the processes that were set in motion in Johannesburg after the end of the apartheid requires using a double lens that highlights not only the visible surface of changes in the built areas, but also the deeper structures that have favored or slowed down the transformation of the cityscape by building and layering sometimes conflicting and ambivalent meanings (dream and nightmare), with images that reveal subsistent and unresolved tensions between the richest and the poorest classes. As a result, Johannesburg has become a symbolic city that epitomizes innovation and its opposite, creativity and destitution, fields of opposing forces that sometimes emerge in unexpected conflicts. The reconstruction of the metropolitan area has produced a sprawling and multi-centric landscape of edge cities connected to the historic urban core by a network of freeways and highways. The downtown business district is inhabited by white collar employees and office workers during the day and by low-income residents and homeless squatters in the evening. In other words, Johannesburg's spatial transformation after the end of apartheid was not the result of a linear process-i.e. progressive horizontal or vertical expansion-but of an overlap of various paths, of beginnings and interruptions, of processes of regeneration and damage that distorted one another's image. Moreover, according to Lefebvre, urban space is not a simple empty container in which social actors move, but a creative social force in which to express tensions and contradictions, urban memories, symbols and meanings that the community attributes to the built environment (Lefebvre, 1991). And the ambivalence of Johannesburg's urban reality itself has fostered among the middle class feelings of anguish and fear, mistrust and indifference towards the poorer classes. The result has been ongoing marginality for all those people who seem not to find a legitimate place in the city, thus feeding an invisible dwelling made of scatterings, rubble and indistinct spaces that have no voice and are not recognized (Landau, 2006; Groth \& Corijn, 2005; Delaney, 2004). Displacement, or the practice of expulsion and exclusion of people who cannot enter an urban space or are forcefully removed from it against their will, is one of the central topics in studying the right to the city, which is linked to the debate on social justice and universal human rights (Bales, 2004; Bauman, 2003; Landau, 2006). Displacement therefore be- 
comes a mind-frame through which power is forced into place and is expressed in terms of exclusion or inclusion, permanently affecting the existence of many people (Kawash, 1998). This profound link between urban space and citizens' rights defines the mechanisms of social inclusion and bases them in the social and cultural fabric of the city and, at the same time, reveals the inability to accommodate the poor by integrating them into the urban life. The absence of adequate housing, the difficulty to access the city's physical and social infrastructure and the lack of legal jobs accentuate the social marginalization of the poorer classes. This condition is partially counterbalanced by the inventiveness and versatility of the poorest urban populations who spontaneously redistribute social goods, and by violating social and spatial rules appropriate what is defined the good city, and determine an insurgent urbanism that seeks to offer an alternative way of living by breaking boundaries and modifying the way spaces should be used according to the planners. At the same time, this condition expresses a negative experience of citizenship for the so-called "non-white majority" of the South African population, resulting in a deprivation of rights, that are attributed only formally but are not actually recognized in everyday life. This unresolved dualism between formal enunciation and daily practice in fact denies the right to the city that Lefebvre talked about (Lefebvre, 1996) and determines forms of daily survival which Holston defines "spaces of insurgent citizenship" (Holston, 1999: pp. 158-159).

Displacement, spatial marginalization and social exclusion of low-income dwellers are the result of the choices made by municipal authorities, the market, policies and regulations that have criminalized urban poverty, identifying it as a structural problem that must be eradicated to shape the city according to the wishes of the middle class (Merrifield, 2000). However, the municipality's inability to respond to the housing demand from the poorest sections of the population has led to informal and unauthorized settlements becoming the only possible option. Social exclusion and marginalization are in fact part of a series of social practices in a social and cultural context that tends to maintain an imbalance in the social order and a condition of instability for the poorest who do not have the ability or the power to organize themselves in a collective and coordinated protest.

Nowadays in Johannesburg, as in many big cities around the world, urban regeneration programmes have transformed some areas of the centre into gentrified neighborhoods, observing the approval of the resident population belonging to the wealthier classes. In fact, gentrification processes, although less frequently than in the United States, Canada and Europe, also occur in African cities. In the 80s and 90s Ponte City, a cylindrical brutalist skyscraper designed in 1975 by Manfred Hermer and Rodney Grosskopff, had turned into a shelter for criminals and quickly became an eyesore. Today it has been turned into the symbol of the conquest of the inner-cities, through a regeneration process that has transformed it into a residential centre for Johannesburg's black middle class. The change in the social destination of the building and the suburb was encouraged 
by huge public investments that were destined to improve its infrastructure, and by the involvement of the real estate market which began to invest in the construction of shopping malls, theatres, night clubs, restaurants and sports centres. So, the middle class, which has been growing steadily since the end of apartheid, has found the right conditions, in terms of social distinction, to move to a place from which the stigma of racial and social segregation had previously driven residents away. In fact, the social transformation of the urban population results not only from deploying economic forces capable of contributing to the development of cities through investments in more profitable real estate operations, but it is also linked to the social and spatial practices of urban restructuring, and to the use of narratives, symbolic images and representations which, recalling the recovery of a lost golden age, influence public opinion and political decision-makers (Mele, 2000). In contrast, in social terms urbanization has had the effect of atomizing society, and the harsh conditions of the urban poor have fuelled social distrust, spreading crime and violence. These two different narrations-decline and regeneration-are used as powerful tools to legitimise urban policies that tend to eliminate, sometimes in a draconian manner, chaos and decay from inner city neighborhoods such as Hillbrow, Berea or Joubert Park. The urban regeneration strategy was founded on confinement and exclusion, and for poor people it represented the negation of the right to the city. Forced removals of poor people did not stop after the end of apartheid, but the lack of awareness of this continuity between the past and the present points to a sort of collective amnesia. The anonymous character of the lives and destiny of displaced people makes them even more vulnerable and prone to being caught up in the various forms of stereotyping (Beningfield \& Gaule, 2006). Said claimed that "for an exile, habits of life, expression, or activity in the new environment inevitably occur against the memory of these things in another environment. Thus both the new and the old environment are vivid, actual, occurring together contrapuntally" (Said, 1999: p. 186). It is this simultaneous double presence that characterizes urban living in South African cities and particularly in Johannesburg.

\section{Conclusion}

South African cities, and especially Johannesburg, still show today the effects of their political history in their urban fabric. In particular, this influence is clear in their irregular development that is also partly due to the attempt to deal with problems related to the deep socio-spatial divisions that defined urban contexts at the end of apartheid. The result was to maintain a strong polarization and to consolidate the presence of informal and segregated settlements. The social policies implemented in the post-1994 period, which were people-centered or based on a pro-poor approach, have paid hardly any attention to spatial inequalities, also due to the difficulty of public decision-makers to rebuild in a unified manner, a fragmented and racially-based system. The South African urban system, and in particular the city of Johannesburg, seem to remain a significant hotbed of exploration and analysis of emerging urban dynamics of the Global South. 
To some extent, these dynamics seem to be similar to those of other cities-including some belonging to the Global North, i.e. the fragmented and sprawling growth of the cities partly express and reflect typical traits of the political history of the country, such as urban segregation patterns and displacement, spatial marginalization and social exclusion of low-income dwellers. At the same time, the entrance into the global market has caused an increase in unemployment, poverty and inequalities in a society that is still looking for a balance between private interest and public good, between economic growth and social fairness and inclusion. In other words, the difficulty of the poorest classes to compete in the market has worsened inequalities and denied them their "right to the city" with regard to several of its main dimensions (especially those that have to do with legal jobs, homes that are not in informal settlements, access to services and urban infrastructures). These sectors of the population have been condemned to constantly being off balance and off place, and have been forgotten or displaced by urban revitalization and regeneration processes.

As a result, alongside the official planning of the city, a parallel scarred city developed that was not planned, whose dwellers redefine the use of spaces and give them a new meaning (in this respect, the evolution of the above-mentioned skyscraper in Ponte City is a significant case). Hence, two cities live side by side in Johannesburg: one that is planned, clearly laid out and predictable, and one that is spontaneous and unpredictable, that follows its own specific rules, that are different from the municipal regulations. The run-down buildings, the dilapidated districts with a high population density, the in-between spaces all represent the urban traces of the different practices of use that have left their mark over time in the city and become a sign and a symbol of the failure of the egalitarian utopia (Jaguaribe, 1999). The key issue is then to respond to the research question concerning whether the informal city is simply a form of survival or whether it represents something more than that. In other words, if the informal city can be considered simply as a part of the city that was defaced and that must be eliminated, made to disappear-thereby following a paradigm that is typical of the Global North-or whether this is just a different language pattern that one must only learn to read and interpret. According to this second possibility, South African cities and Johannesburg in particular might represent a perfect hotbed to experiment a new form of hybrid governance that is based on the mutual acceptance of two different ways of understanding urban living, of two rational orders (Trefon, 2009; Myers, 2010). The second option that recognizes alternative forms of planning generated by informality certainly seems more exciting. As a matter of fact, the analysis of the evolution of the city of Johannesburg shows how its resident did not passively witness events, but rather created and produced useful strategies for their self-sufficiency and survival (Konings \& Foeken, 2006: p. 3). Some scholars see informality as a resource, others blame it for the crisis of South African cities, while still others point out the dichotomy that it generates in the urban form and that manifests itself in the alternation between creation and destruction, thus clearly showing the whole 
complexity of the research area. However, even though the international debate is still open, the idea is taking hold that informality can be considered a hybrid organizational logic that forces the rethinking of the current interpretative categories, including "formal" and "informal", of the narrative of the urban poor (even if in the awareness of a broad global trend of weak commitment to the poor-Amin \& Thrift, 2018: p. 142) and of the paradigms that are predominantly used. From this point of view, Johannesburg's urban spaces can be considered also very progressive politically, socially and culturally, making them hotbeds for some of the most exciting thinkers and artists who create interesting and prolific subcultures. This aspect on the one hand highlights the importance of the organizational capacity and resources of the poorest populations, and on the other underlines the need to study townships and informal settlements, their inhabitants and their living conditions, to avoid that what is already invisible also becomes unheard. According to Amin and Thrift (2018), restoring the agency of poor people and their settlements and opening new options for a politics of provisioning for the poor could lead to the unification of two different cities within a unified vision.

\section{Conflicts of Interest}

The author declares no conflicts of interest regarding the publication of this paper.

\section{References}

AlSayyad, N. (2004). Urban Informality as a "New" Way of Life. In A. Roy, \& N. AlSayyad (Eds.), Urban Informality: Transnational Perspectives from the Middle East, Latin America, and South Asia (pp. 7-30). Lanham, MD: Lexington Books.

Amin, A., \& Thrift, N. (2018). Seeing Like a City. Cambridge: Polity Press.

Bales, K. (2004). Disposable People: New Slavery in the Global Economy. Berkeley, CA: University of California Press.

Bauman, Z. (2003). Wasted Lives: Modernity and Its Outcasts. Cambridge, UK: Polity Press.

Beavon, K. (1992). Some Alternative Scenarios for the South African City in the Era of Late Apartheid. In D. Drakakis-Smith (Ed.), Urban and Regional Change in Southern Africa (pp. 66-99). London: Routledge.

Beningfield, S., \& Gaule, S. (2006). Circuits of Power and Powerlessness: Newtown. Leading Architecture and Design, (January-February), 24-26.

Boraine, A. et al. (2006). The State of South African Cities a Decade after Democracy. Urban Studies, 43, 259-284. https://doi.org/10.1080/00420980500416990

Christopher, A. J. (2000). The Atlas of Changing South Africa. London: Routledge.

Comaroff, J., \& Comaroff, J. L. (2012). Theory from the South: Or, How Euro-America Is Evolving toward Africa. Anthropological Forum, 22, 113-131. https://doi.org/10.1080/00664677.2012.694169

Dados, N., \& Connell, R. (2012). The Global South. Contexts, 11, 12-13. https://doi.org/10.1177/1536504212436479

Davies, R. J. (1981). The Spatial Formation of the South African City. GeoJournal, 2, 


\section{9-72. https://doi.org/10.1007/BF00196325}

Davies, R. J. (1996). Contemporary City Structuring: International Geographical Insights. Cape Town: Society of South African Geographers.

De Boeck, F. (2002). Kinshasa: Tales of the Invisible City and the Second World. In O. Enwezor et al. (Eds.), Under Siege: Four African Cities-Freetown, Johannesburg, Kinshasa, Lagos. Ostfildern-Ruit, Germany: Hatje Cantz.

Delaney, D. (2004). Tracing Displacements: Or, Evictions in Nomosphere. Environment and Planning, 22, 847-860. https://doi.org/10.1068/d405

Erasmus, B. P. J. (2014). On Route in South Africa. Jeppestown: Jonathan Ball Publishers.

Ferguson, J. (2006). Global Shadows: Africa in the Neoliberal World Order. Durham, NC: Duke University Press. https://doi.org/10.1215/9780822387640

Groth, J., \& Corijn, E. (2005). Reclaiming Urbanity: Indeterminate Spaces, Informal Actors, and Urban Agenda Setting. Urban Studies, 42, 503-526. https://doi.org/10.1080/00420980500035436

Hart, G. (1989). On Grey Areas. South African Geographical Journal, 71, 81-88. https://doi.org/10.1080/03736245.1989.9713514

Holston, J. (1999). Space of Insurgent Citinzenship. In J. Holston, \& A. Appadurai (Eds.), Cities and Citizenship (pp. 155-173). Durham, NC: Duke University Press. https://doi.org/10.2307/j.ctv11cw70j.11

Howard, E. (1945). Garden Cities of Tomorrow. London: Faber and Faber.

Jacobs, S. (2006). Sur l'Afrique du Sud post-apartheid et le devenir de la nation “arc-en-ciel”. Politique Africaine, 3, 5-26. https://doi.org/10.3917/polaf.103.0005

Jaguaribe, B. (1999). Modernist Ruins: National Narratives and Architectural Forms. Public Culture, 11, 294-312. https://doi.org/10.1215/08992363-11-1-295

Kawash, S. (1998). The Homeless Body. Public Culture, 10, 319-339. https://doi.org/10.1215/08992363-10-2-319

Konings, P., \& Foeken, D. (2006). Crisis and Creativity: Exploring the Wealth of the African Neighborhood. Leiden: Brill.

Koolhaas, R., \& Harvard Project on the City (2001). Mutations. Bordeaux: Arc en Rêve Centre d'Architecture.

Kotze, N. J., \& Donaldson, S. E. (1998). Residential Desegregation in Two South African Cities: A Comparative Study of Bloemfontein and Pietersburg. Urban Studies, 35, 467-477. https://doi.org/10.1080/0042098984862

Landau, L. (2006). Transplants and Transients: Idioms of Belonging and Dislocation in Inner-City Johannesburg. African Studies Review, 49, 125-145. https://doi.org/10.1353/arw.2006.0109

Lefebvre, H. (1991). The Production of Space. New York: Blackwell.

Lefebvre, H. (1996). Writings on Cities. Oxford: Blackwell.

Lemon, A. (1991). Homes Apart: South Africa's Segregated Cities. London: Paul Chapman.

Mbembe, A., \& Nuttall, S. (2004). Writing the World from an African Metropolis. Public Culture, 16, 349-372. https://doi.org/10.1215/08992363-16-3-347

Mbembe, A., \& Nuttall, S. (2008). Introduction: Afropolis. In S. Nuttall, \& A. Mbembe (Eds.), Johannesburg: The Elusive Metropolis (pp. 1-33). Durham, NC: Duke University Press. https://doi.org/10.1215/9780822381211

Mele, C. (2000). The Materiality of Urban Discourse: Rational Planning in the Restructuring of the Early Twentieth-Century Ghetto. Urban Affairs Review, 35, 628-648. 


\section{https://doi.org/10.1177/10780870022184570}

Mennasemay, M. (2009). A Millennium Development Goal for Ethiopia: Some Conceptual Issues. Africa Today, 55, 3-32. https://doi.org/10.2979/AFT.2008.55.1.2

Merrifield, A. (2000). The Dialectics of Dystopia: Disorder and Zero Tolerance in the City. International Journal of Urban and Regional Research, 24, 473-489. https://doi.org/10.1111/1468-2427.00259

Murray, M. (2009). Fire and Ice: Unnatural Disasters and the Disposable Urban Poor in Post-Apartheid Johannesburg. International Journal of Urban and Regional Research, 33, 165-192. https://doi.org/10.1111/j.1468-2427.2009.00835.x

Murray, M. (2011). City of Extremes: The Spatial Politics of Johannesburg. Durham, NC: Duke University Press. https://doi.org/10.1215/9780822391814

Murray, M. (2017). Timing the Disorderly City. The Spatial Landscape of Johannesburg after Apartheid. Ithaca, NY: Cornell University Press.

Myers, G. (2010). Social Construction of Peri-Urban Places and Alternative Planning in Zanzibar. African Affairs, 109, 575-595. https://doi.org/10.1093/afraf/adq044

Nussbaum, M., \& Sen, A. (1993). Introduction. In M. Nussbaum, \& A. Sen (Eds.), The Quality of Life (pp. 1-6). Oxford: Clarendon Press.

Oelofse, G., \& Dodson, B. (1997). Community, Place and Transformation: A Perceptual Analysis of Residents' Responses to an Informal Settlement in South Africa. Geoforum, 28, 91-101. https://doi.org/10.1016/S0016-7185(97)85529-7

Parker, S. (2015). Urban Theory and the Urban Experience: Encountering the City. London: Routledge. https://doi.org/10.4324/9780203122402

Parnell, S., \& Robinson, J. (2012). (Re)theorizing Cities from the Global South: Looking beyond Neoliberalism. Urban Geography, 33, 593-617.

https://doi.org/10.2747/0272-3638.33.4.593

Said, E. W. (1999). Reflection on Exile and Other Essays. Cambridge, MA: Harvard University Press.

Schoenkopf, J. (2018). Imaginary Johannesburg. https://www.academia.edu/38460461/imaginary.johannesburg 7 .pdf

Sen, A. (1993). Capability and Well-Being. In M. Nussbaum, \& A. Sen (Eds.), The Quality of Life (pp. 30-53). Oxford: Clarendon Press.

Sen, A. (1999). Development as Freedom. New York: Alfred P. Knopf.

Tomlinson, R. (1990). Urbanization in Post-Apartheid South Africa. London: Unwin Hyman.

Trefon, T. (2009). Hinges and Fringes. Conceptualizing the Per-Urban in Central Africa. In F. Locatelli, \& P. Nugent (Eds.), African Cities: Competing Claims on Urban Spaces (pp. 15-36). Leiden: Brill. https://doi.org/10.1163/ej.9789004162648.i-308.9

UN-DESA (2015). The World Population Prospects: The 2015 Revision. New York: United Nations.

United Nations (2019). World Social Situation 2019: Shaping the Future of Inequality. New York: United Nations.

Western, J. (1996). Outcast Cape Town. Berkeley, CA: University of California Press. 